\title{
The operating room dance
}

\section{Julie Ann Freischlag}

Gillespie and colleagues have reported on their structured observations in operating rooms to help us understand which factors (interruptions, communication failures, team familiarity and the unpredictability of unplanned cases) prolong the length of an operation and lead to inefficiency and increased costs. All of us feel intuitively that a well-orchestrated operation is best for everyone involved-the patient, the surgeon, the anaesthesiologist, the nurse and the hospital's bottom line. Communication failures have been identified by Makary and others to cause the majority of errors in the operating room as reviewed retrospectively. ${ }^{1-3}$ This paper is one of the very first to observe communication failures in real time and connect those communication failures to a longer than expected operating time.

In order to improve communication, many operating room teams have expanded the perioperative timeout to a briefing. The briefing contains more information and is meant to be a conversation about the patient between the surgeon, nurse and anaesthesiologist. This briefing can identify any unusual issues with the patient that everyone should be aware of, can identify the need for any special equipment or implants and can introduce the members of the team for the proce-

Correspondence to Dr Julie Ann Freischlag, Department of Surgery, Johns Hopkins, 720 Rutland Avenue 759 Ross, Baltimore, MD 21205, USA; jfreisc1@jhmi.edu dure. Getting everyone on the same page is critical.

Likewise, debriefings have been instituted at Johns Hopkins to discuss how the case went and to delineate what the patient will need in the postanaesthesia care unit, pain medication, radiographs, need for an intensive care unit bed, blood products or other concerns. ${ }^{3}$ It is always easier to discuss a case that has gone well than one that did not go well. Sometimes that discussion needs to be done a bit later so that everyone can reflect and gain perspective, especially if the patient is not doing well at the end of the case.

As pointed out by the authors, there is a lot of informal communication during an operation. This can be just day-to-day conversation (How is the weather? What are you doing this weekend? etc) or it can be teaching as seen in academic healthcare centres. Some operating rooms have music playing. Some operating rooms are quieter-a lot depends on the preferences of the operating surgeon. These interruptions can be managed by the team, as these conversations do enhance the feeling of a team and can enhance the feeling in the overall environment.

Communication can augment or detract from the progress of an operation. If the surgeon has a good rapport with the others in the room, even if there is a stressful moment during the operation-such as bleeding or a malfunctioning piece of equipment-tension isles and solutions are found and discussions occur. By contrast, a surgeon who yells at the team makes progress halt and no one dares to speak. I have been in both kinds of operating rooms in my career and have opted for the first as, overall, I feel better without screaming and tension.

I equate the operating room environment to a dance. One can choose the music and the tempo, sometimes you can even choose your partner-the first assistant, the scrub technologist and even the anaesthesiologist-but you start dancing anyway because there is an operation to do. If you have an unfamiliar partner, more words need to be spoken about your steps, and you go a bit slower initially. However, you can still enjoy the dance, as that is what you love to do.

In our video on how to do briefings and debriefings, I ask the question 'What would you want us to be talking about if you were the patient on the operating room table?' Of course, you would want us to be talking about you and your operation and you would want us to be communicating well throughout the entire course of your operation. No matter if we were doing a waltz, a tango or the twist.

Competing interests None.

Provenance and peer review Commissioned; internally peer reviewed.

Published Online First 18 November 2011

BMJ Qual Saf 2012;21:1.

doi:10.1136/bmjqs-2011-000517

\section{REFERENCES}

1. Makary MA, Mukherjee A, Sexton JB, et al. Operating room briefings and wrong-site surgery. J Am Coll Surg 2007;204: 236-43.

2. Makary MA, Sexton JB, Freischlag JA, et al. Operating room teamwork among physicians and nurses: teamwork in the eye of the beholder. J Am Coll Surg 2006;202:746-52.

3. Nundy S, Mukherjee A, Sexton JB, et al. Impact of preoperative briefings on operating room delays: a preliminary report. Arch Surg 2008;143:1068-72. 